\title{
Stereological Analysis of Interdental Gingiva in Chronic Periodontitis Patients With Tumor Necrosis Factor-alpha (-308 G/A) Gene Polymorphisms
}

\author{
Zahra Heidari ${ }^{1,2}$; Hamidreza Mahmoudzadeh-Sagheb ${ }^{1,2,{ }^{*}}$; Mohammad Hashemi ${ }^{3,4}$; \\ Mohammad Ayub Rigi-Ladiz ${ }^{5}$ \\ ${ }^{1}$ Genetic of Non-communicable Diseases Research Center, Zahedan University of Medical Sciences, Zahedan, IR Iran \\ ${ }_{2}^{2}$ Department of Histology, School of Medicine, Zahedan University of Medical Sciences, Zahedan, IR Iran \\ ${ }^{3}$ Cellular and Molecular Research Center, Zahedan University of Medical Sciences, Zahedan, IR Iran \\ ${ }^{4}$ Department of Clinical Biochemistry, School of Medicine, Zahedan University of Medical Sciences, Zahedan, IR Iran \\ 5 Department of Clinical Biochemistry, School of Medicine, Zahedan University of Medical Sciences, Zahedan, \\ ${ }^{*}$ Corresponding author: Hamidreza Mahmoudzadeh-Sagheb, Department of Histology, School of Medicine, Zahedan University of Medical Sciences, Zahedan, IR Iran. Tel: +98- \\ 5413414572, Fax: +98-5413414572, E-mail: histology@ymail.com
}

Received: February 1, 2014; Revised: February 9, 2014; Accepted: February 17, 2014

\begin{abstract}
Background:The association between tumor necrosis factor-alpha (TNF- $\alpha)(-308 \mathrm{G} / \mathrm{A})$ gene polymorphisms and level of tissue destruction and periodontal disease progression is not proved.

Objectives: The present study investigated the stereological parameters of interdental papilla in chronic periodontitis (CP) patients with TNF- $\alpha(-308 \mathrm{G} / \mathrm{A})$ gene polymorphisms.

Materials and Methods: Sixty gingiva samples were studied. After determination of TNF- $\alpha(-308 \mathrm{G} / \mathrm{A})$ gene polymorphisms using a tetra amplification refractory mutation system-polymerase chain reaction (T-ARMS-PCR) technique, 45 gum tissues of CP patients (40 GG, 4 GA+1 AA genotype) were considered as the case group. Fifteen control samples were also collected from healthy individuals. Interdental gingiva tissues were fixed in Lilli's solution and after tissue processing were exhaustively sectioned into $4 \mu \mathrm{m}$ thick sections. Ten to 13 sections were sampled by systematic uniform random sampling(SURS), stained with Masson's trichrome and then the volume fractions; volume per unit volume (Vv) of the gingival components were estimated using Cavalier's point counting method.

Results: There were statistically significant differences in the $\mathrm{Vv}$ of epithelium, connective tissue, collagenous and non-collagenous matrix and blood vessels between the control and CP groups $(\mathrm{P}<0.0001)$. There were no statistically significant differences in the $\mathrm{Vv}$ of epithelium, connective tissue of gingiva, collagenous and non-collagenous matrix and blood vessels between GG, GA, and AA genotypes in $\mathrm{CP}$ patients $(\mathrm{P}>0.05)$.

Conclusions: Results of the current study showed that there was no association between TNF- $\alpha(-308 \mathrm{G} / \mathrm{A})$ gene polymorphisms and quantitative parameters of interdental papilla in CP patients.
\end{abstract}

Keywords:Chronic Periodontitis; Gingiva; Tumor Necrosis Factor-alpha; Gene; Polymorphism, Genetic

\section{Background}

Chronic periodontitis (CP) is an infectious inflammatory disease characterized by the destruction of toothsupporting structures, where the presence of specific microorganisms are required, but not sufficient for disease development (1). Cytokine networks play an important role in the initiation and progression of periodontal disease. Pro-inflammatory cytokines play crucial roles in microbe-induced destructive inflammation (2). During the progression of periodontal inflammation, periodontal ligament and gingival fibroblasts secrete high levels of cytokines and chemokines (3). Production of numerous pro-inflammatory cytokines is amplified by several bacteria-derived virulence factors, thereby leading to the destruction of soft tissues and bones (4). Tumor necrosis factor-alpha (TNF- $\alpha$ ) is a cytokine that has been implicated in periodontal disease due to its effects on bone and soft tissue metabolism (4). It is an endotoxin induced macrophage hormone, which is implicated in the pathogenesis of shock and cachexia (5). It has a high potential for increasing bone resorption and is involved in the degradation of connective tissue by stimulating prostaglandin-E2 and Collagenase, respectively (4). Several studies have reported elevated levels of TNF- $\alpha$ in both GCF and gingival tissue biopsies from periodontal disease sites of humans. Furthermore, blockage of the activity of TNF- $\alpha$ was found to slow down the progression of experimental

Implication for health policy/practice/research/medical education:

This article focuses on stereological analysis of interdental papilla in chronic periodontitis (CP) patients with TNF- $\alpha$ (-308 G/A) gene polymorphisms. Tumor necrosis factor-alpha (TNF- $\alpha$ ) is a cytokine implicated in periodontal disease due to its effects on bone and soft tissue metabolism. This polymorphism affects the expression of TNF- $\alpha$. Considering these points, it is necessary to find out the association between this polymorphism and stereological parameters of interdental gingiva. This study is recommended to the researchers in the fields of basic medical sciences especially geneticist, histologists, pathologists and oral clinicians and dentists, and also for enlightening the minds of general population.

Copyright (C) 2014, Zahedan University of Medical Sciences. This is an open-access article distributed under the terms of the Creative Commons Attribution License, which permits unrestricted use, distribution, and reproduction in any medium, provided the original work is properly cited. 
periodontitis in primates (6-8).

TNF- $\alpha$ is known to be the most important pro-inflammatory cytokine released at the site of periodontal disease and is considered as the most potent osteoclast activating factor (OAF) (9). A number of studies have shown a close association between TNF- $\alpha$ level and periodontal disease severity and also some studies showed that, during active periodontitis, TNF- $\alpha$ served as a marker of tissue destruction, bone resorption (10-13), and clinical severity (7). TNF- $\alpha$ inhibits collagen synthesis and at high concentrations stimulates collagenase synthesis in fibroblasts (14). Polymorphisms in genes that encode immunological molecules such as pro-inflammatory cytokines have been targeted as potential genetic markers for periodontitis. These cytokines play an important role in the initiation and amplification of the inflammatory response $(15,16)$. The biological basis for the association between cytokine gene polymorphism and periodontal disease is that carriage of certain alleles is suspected to cause changes in the production of a given mediator (12). Numerous studies suggest that the severity of periodontitis may differ in carriers of rare alleles of single cytokines, such as the 308 A allele of tumor necrosis factor- $\alpha$ (TNF- $\alpha)$ gene $(10,17-$ 19). Polymorphisms in the promoter region of the TNF- $\alpha$ gene at position $(308, G$ to $A$ ) have been evaluated $(13,20$, 21). The $308 \mathrm{~A}$ allele has been associated with high level of promoter activity, and enhanced TNF- $\alpha$ production $(10,22)$. Galbraith et al. (23) found that patients with periodontal disease carrying the rare allele at position 308 of the TNF- $\alpha$ gene had higher TNF- $\alpha$ production than the non-carriers. More studies are required in order to verify the association of TNF- $\alpha$ gene polymorphisms with the level of tissue destruction and periodontal disease progression. To date, there has been no data concerning the stereological parameters of gingival tissues of individuals with TNF- $\alpha$ gene polymorphisms.

\section{Objectives}

The present study investigated the stereological parameters of interdental gingiva in CP patients with TNF- $\alpha$ $(-308 \mathrm{G} / \mathrm{A})$ gene polymorphisms.

\section{Materials and Methods}

\subsection{Sample Selection}

The patients were selected according to the criteria specified in the international workshop for classification of periodontal diseases and conditions (24). The patients were non-smokers and none of them had a history or current manifestation of systemic diseases. Patients with severe medical disorders such as diabetes mellitus, immunological disorders, hepatitis and pregnant women were excluded from the study. After approval of the University Ethics Committee (No. 89-2880) and obtaining written informed consent from the participants, $2 \mathrm{~mL}$ peripheral venous blood were collected in Na-EDTA tubes from each subject to detect TNF- $\alpha(-308 \mathrm{G} / \mathrm{A})$ polymorphisms.

\subsection{DNA Extraction and Genotyping}

DNA was extracted from whole blood by salting out method as described previously (16). A Tetra primer amplification refractory mutation system-polymerase chain reaction (TARMS-PCR) was designed to detect TNF- $\alpha(-308$ G/A) polymorphisms (25).

\subsection{Preparation of Tissues and Stereological Study}

Tissue preparation was done, according to the protocol described (3), as follows: After determination of (TNF- $\alpha$ ) $(-308 \mathrm{G} / \mathrm{A})$ gene polymorphisms using T-ARMS-PCR, 45 interdental gingiva tissues (40 GG, 4 GA+1 AA genotype) were considered as the case group. Because of only one sample with AA genotype, the GA and AA genotypes were considered as a group and were compared with the GG genotype group. The gingiva in the control group $(n=15)$ were obtained during tooth extraction for orthodontic or prosthodontic treatments from the persons with clinically healthy gingiva. The mean age in the chronic periodontitis group was $42.2 \pm 8.93$, and in the control was $39.5 \pm$ 8.19 years. The interdental papilla tissues were immersed in Lillie's fixative solution for one week at room temperature. After tissue processing and embedding in paraffin wax, each interdental gingiva sample was exhaustively sectioned into $4 \mu \mathrm{m}$ thick sections. Ten to 13 sections were sampled from each specimen by systematic uniform random sampling (SURS) $(3,26)$. The first section of tissue was randomly obtained between 1 to 200 micron and the next sections with a 200 micron distance were selected by SURS and stained with Masson's trichrome. Cavalier's point counting method was employed to estimate the volume of interdental papilla (3). On each sampled section six to eight fields were selected in a SURS manner. A test system of points was then superimposed on these fields and points hitting the various components of the tissue were counted. Then an estimate of the volume density (Vv) of the components in the reference space was obtained using:

$\mathrm{Vv}=\mathrm{P}($ part $) / \mathrm{P}$ (ref)

Where, $P$ (part) and $P$ (ref) are respectively the number of test points falling in all structure profiles and in the reference space $(3,27)$. All stereological analyses were done by two expert histologists on blind-coded slides.

\subsection{Statistical analysis}

Data were presented as means \pm SD and 95\% confidence interval $(95 \% \mathrm{CI})$. Student t test was used to compare differences between groups. Significant level was $\mathrm{P}<0.05$. All statistical analyses were performed employing SPSS version 16.0 for Windows software system. 
Heidari Z et al.

\section{Results}

Histological structure of $\mathrm{C}$ and CP patients are shown in Figure 1 and Figure 2. Quantitative analysis of gingival sample indicated that there were statistically significant differences in the volume density (Vv) of epithelium, connective tissue, collagenous and non-collagenous matrix, and blood vessels between control and all chronic periodontitis groups $(\mathrm{P}<0.0001)$ (Table 1$)$. There were no statistically significant differences in the $\mathrm{Vv}$ of epithelium and connective tissue of gingiva, collagenous and noncollagenous matrix and blood vessels between GG, and GA+AA groups $(\mathrm{P}>0.05)$ (Table 2 ).

\section{Discussion}

Results of the current study indicated that there were statistically significant differences in quantitative parameters of interdental gingiva between the $\mathrm{CP}$ patients and the healthy controls. It is well known that in periodontal diseases there is local infiltration of inflammatory cells associated with a degradation of extracellular matrix (ECM) macromolecules. Collagen fibers quantitatively constitute the major component of the ECM of gingival connective tissue, and have a primordial role in its architecture. Loss of the collagen component may reflect the severity of the $\mathrm{CP}(3,28-30)$. Results of the current study showed that there was a statistically significant difference in the $\mathrm{Vv}$ of gingival epithelium and connective tissue between the CP patients and the healthy controls. The gingival epithelium is the most external tissue compartment mainly implicated in the defense of the deeper periodontal tissues, and it is an important physical barrier against external pathogens. Increment of $\mathrm{Vv}$ of epithelium might be due to hyperplasia and infiltration of inflammatory cells in epithelium (3). Several studies have suggested a substantial genetic influence in CP. Host modifying factors associated with severe periodontitis suggest a biological mechanism by which some individuals, if challenged by bacterial accumula- tions, may have a more vigorous immune-inflammatory response, leading to more severe clinical diseases (31).

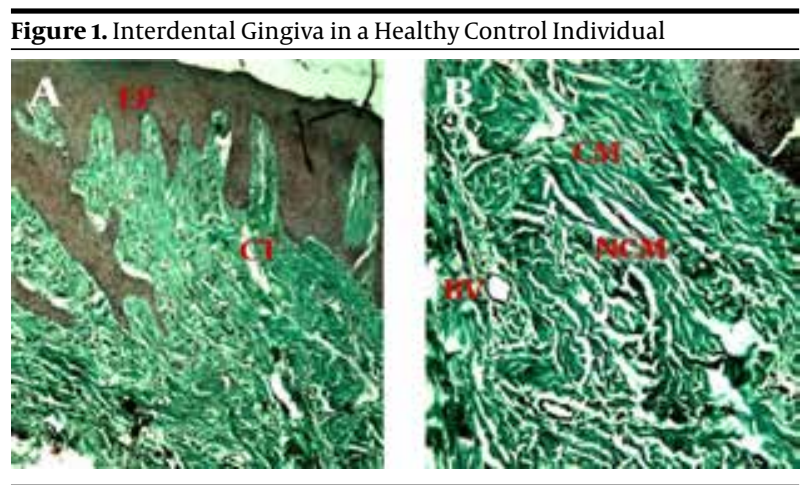

A) Consists of a surface epithelium (EP) and supporting connective tissue (CT) $(40 \mathrm{x})$. B) Gingival connective tissue in the control sample consists of collagenous matrix (CM), and non-collagenous compartment that in turn comprises non-collagenous matrix (NCM) and blood vessels (BV) $(100 \mathrm{x})$.

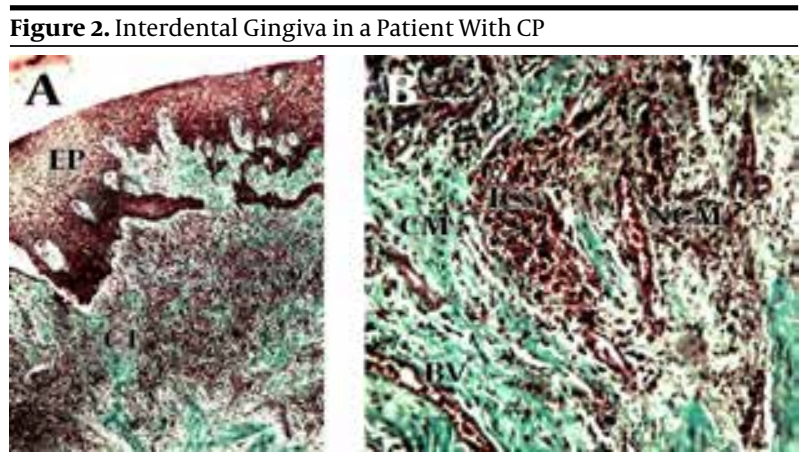

A) consists of a surface epithelium (EP) and supporting connective tissue (CT) $(40 \mathrm{x})$. B) Gingival connective tissue consists of collagenous matrix (CM) and non-collagenous compartment that in turn comprises noncollagenous matrix (NCM) and blood vessels (BV), note degradation of collagenous extracellular matrix (CM) associated with an infiltration of several inflammatory cell populations in non-collagenous matrix (NCM) ,increment of blood vessels (BV) and infiltration of inflammatory cells (ICs) $(100 \mathrm{x})$.

Table 1. Quantitative Parameters of Interdental Gingiva in Chronic Periodontitis Patients and Healthy Controls a,b

\begin{tabular}{|c|c|c|c|c|c|}
\hline \multirow[t]{2}{*}{ Volume density } & \multicolumn{2}{|c|}{$C P(n=45)$} & \multicolumn{2}{|c|}{ Control $(n=15)$} & \multirow[t]{2}{*}{ PValue $^{\mathrm{C}}$} \\
\hline & Results, mean \pm SD & 95\% CI & Results, mean \pm SD & 95\% CI & \\
\hline Epithelium & $36.7 \pm 4.32$ & $35.44-38.03$ & $27.8 \pm 3.73$ & 25.74-29.86 & $<0.0001$ \\
\hline Connective tissue & $63.3 \pm 4.32$ & $62.00-64.56$ & $72.2 \pm 3.73$ & $70.14-74.26$ & $<0.0001$ \\
\hline Collagenous matrix & $35.4 \pm 7.14$ & $33.21-37.50$ & $58.3 \pm 3.35$ & $56.48-60.19$ & $<0.0001$ \\
\hline Non-collagenous compartment & $27.7 \pm 6.11$ & $25.90-29.57$ & $15.6 \pm 3.37$ & $13.39-16.75$ & $<0.0001$ \\
\hline Blood vessel & $16.3 \pm 4.56$ & $14.90-17.64$ & $8.8 \pm 1.82$ & $7.79-9.81$ & $<0.0001$ \\
\hline Non-collagenous matrix & $11.7 \pm 5.48$ & $10.02-13.35$ & $6.6 \pm 2.59$ & $5.13-7.94$ & $<0.0001$ \\
\hline
\end{tabular}

\footnotetext{
a Abbreviations: $\mathrm{CI}$, confidence interval; $\mathrm{CP}$, chronic periodontitis

$\mathrm{b}$ Data are presented in percentage.

${ }^{\mathrm{c}} \mathrm{P}<0.0001$ compared to the control group
} 
Heidari Z et al.

Table 2. Quantitative Parameters of Interdental Gingiva in Chronic Periodontitis Patients With TNF- $\alpha(-308$ G/A) Gene Polymorphisms (GG and GA+ AA genotypes) ${ }^{\mathrm{a}}$, b

\begin{tabular}{lccccc}
\hline \multirow{2}{*}{ Volume density } & \multicolumn{2}{c}{ GG Genotype $(\mathbf{n}=\mathbf{4 0})$} & \multicolumn{2}{c}{ GA + AA Genotype $(\mathbf{n}=\mathbf{1 5})$} & \multicolumn{2}{c}{ PValue $^{\mathrm{c}}$} \\
\cline { 2 - 7 } & Results, mean \pm SD & $\mathbf{9 5 \%}$ CI & Results, mean \pm SD & \multicolumn{2}{c}{$\mathbf{9 5 \% \text { CI }}$} \\
\hline Epithelium & $36.6 \pm 4.42$ & $35.18-38.02$ & $37.8 \pm 3.56$ & $33.38-42.22$ & NS \\
Connective tissue & $63.4 \pm 4.42$ & $61.98-64.82$ & $62.2 \pm 3.56$ & $57.78-66.62$ & NS \\
Collagenous matrix & $35.5 \pm 7.42$ & $33.10-37.9$ & $34.4 \pm 4.72$ & $28.54-40.26$ & NS \\
Non-collagenous compartment & $27.7 \pm 6.31$ & $25.71-29.74$ & $27.8 \pm 4.66$ & $22.02-33.58$ & NS \\
Blood vessel & $16.2 \pm 4.74$ & $14.71-17.74$ & $16.6 \pm 3.21$ & $12.62-20.58$ & NS \\
Non-collagenous matrix & $11.8 \pm 5.68$ & $9.93-13.57$ & $11.2 \pm 2.77$ & $7.75-14.65$ & NS \\
\hline
\end{tabular}

a Abbreviation: NS, not significant

${ }^{b}$ Data are presented in percentage.

c One way ANOVA

Among the host proteases that target the ECM, the matrix metalloproteinases (MMPs) have been especially associated with the remodeling of periodontal tissues. MMPs are usually found in balance with a group of endogenous proteins named tissue inhibitors of metalloproteinases (TIMPs), to keep matrix remodeling highly regulated. In fact, MMPs and TIMPs are regularly expressed in healthy periodontal tissues, where they are supposed to control the ECM physiological turnover (1). While the presence of periodontal pathogens is required, but not sufficient, for disease onset, studies have clearly demonstrated that the host response plays a critical role in periodontal tissue breakdown (32). TNF- $\alpha$ acts in the cell migration process at multiple levels, inducing the up-regulation of adhesion molecules and the production of chemokines, which are chemotactic cytokines involved in cell migration to infected and inflamed sites. Supporting the data from human studies, analysis of data for experimental periodontal disease in rats and primates clearly demonstrated that TNF- $\alpha$ plays a central role in inflammatory reaction, alveolar bone resorption, and the loss of connective tissue attachment (1). In addition to presenting a direct effect on the pathogenesis of PD, TNF- $\alpha$ up-regulates the production of other classic pro-inflammatory innate immunity cytokines, such as IL-1 $\beta$ and IL-6. Interestingly, IL-1 $\beta$ and IL- 6 have been characteristically associated with inflammatory cell migration and osteoclastogenesis processes $(1,32)$. Several genetic, environmental, ethnical, and sexual factors as well as the type of periodontal bacteria can affect the disease process. There are strong evidences indicating greater impact of genetic factors than environmental ones on periodontitis development (25). Polymorphisms in genes encoding molecules of the host defense system, such as cytokines, have been targeted as potential genetic markers. It is conceivable that individual differences in periodontitis susceptibility or individual differences in CP severity are related to genetically determined differences in TNF- $\alpha$ production and secretion by a variety of cells. It has been shown that carriers of the TNF- $\alpha 308$ A allele appeared to have greater transcription activity, and produced higher levels of TNF- $\alpha$ (33). Moreover there was a higher prevalence of allele A TNF- $\alpha-308$ in periodontitis patients compared to those suffering from gingivitis (23). TNF- $\alpha$ (-308 A > G) gene polymorphism affects the expression of this cytokine. In addition, the presence of A allele in this region was accompanied by increased level of TNF- $\alpha$ and intensified periodontal disease $(34,35)$. On the other hand, de Jong et al. suggested that TNF gene polymorphisms were not related to differences in levels of endotoxin induced TNF production in whole blood samples (36). The authors' previous study also indicated that there was no association between TNF- $\alpha$ (-308G $>$ A) polymorphism and chronic periodontitis in the population (25). Results of the present study showed that there was no statistically significant difference in the Vv of epithelium, connective tissue, collagenous matrix and non-collagenous compartment of gingival connective tissue and blood vessels between GG, and GA+ AA polymorphisms of TNF- $\alpha(-308 \mathrm{G} / \mathrm{A})$ gene polymorphisms in CP patients. One reason for these results may be population heterogeneity. Disease prevalence pattern often changes with geography and ethnic origin, and allele frequencies can vary widely worldwide. In other words, a different allele of a single SNP may be a marker for certain phenotype in different population samples. A genetic risk factor for disease susceptibility in one population may not be a risk factor in another population sample (16). The limitation of this study was its relatively small sample size. Consequently, subgroup analysis was not possible. Larger studies are needed to confirm these findings on the relationships of genetic variations to the pathogenesis of CP. However, more comprehensive studies in larger groups of patients on genotype and allele diversity of TNF- $\alpha$ gene polymorphism, and molecular mechanisms by which TNF- $\alpha$ is involved in susceptibility to CP are necessary.

\section{Acknowledgements}

The project was funded by Zahedan University of Medical Sciences; grant no. 112-26-2011. The authors wish to 
acknowledge the patients and healthy subjects who willingly participated in the study.

\section{Authors' Contribution}

Z. Heidari and H. Mahmoudzadeh-Sagheb conceived and co-designed the study, supervised all the experimental design, analyzed the results, and drafted the manuscript. M. Hashemi contributed in study design and coordination, supervised the genetic assays and statistical analyses and the interpretation of results and the manuscript. M. Rigi-Ladez performed patient selection and participated in data collection. All authors read, modified and approved the final version of the manuscript.

\section{Financial Disclosure}

None of the authors has any financial or other interest in the dissemination of this article.

\section{Funding/Support}

The present study was supported by the vice chancellor of Research and Technology of Zahedan University of Medical Sciences.

\section{References}

1. Garlet GP. Destructive and protective roles of cytokines in periodontitis: a re-appraisal from host defense and tissue destruction viewpoints. J Dent Res. 2010;89(12):1349-63.

2. Morandini AC, Sipert CR, Ramos-Junior ES, Brozoski DT, Santos CF. Periodontal ligament and gingival fibroblasts participate in the production of TGF-beta, interleukin (IL)-8 and IL-10. Braz Oral Res. 2011;25(2):157-62.

3. Heidari Z, Mahmoudzadeh-Sagheb H, Hashemi M, Rigi-Ladiz MA. Quantitative Analysis of Interdental Gingiva in Patients With Chronic Periodontitis and Transforming Growth Factor-beta1 29C/T Gene Polymorphisms. J Periodontol. 2014;85(2):281-9.

4. Morimoto Y, Kawahara KI, Tancharoen S, Kikuchi K, Matsuyama T, Hashiguchi T, et al. Tumor necrosis factor-alpha stimulates gingival epithelial cells to release high mobility-group box $1 . J$ Periodontal Res. 2008;43(1):76-83.

5. Dayer JM, Beutler B, Cerami A. Cachectin/tumor necrosis factor stimulates collagenase and prostaglandin E2 production by human synovial cells and dermal fibroblasts. J Exp Med. 1985;162(6):2163-8.

6. Shapira L, Stabholz A, Rieckmann P, Kruse N. Genetic polymorphism of the tumor necrosis factor (TNF)-alpha promoter region in families with localized early-onset periodontitis. J Periodontal Res. 2001;36(3):183-6.

7. Ejeil AL, Gaultier F, Igondjo-Tchen S, Senni K, Pellat B, Godeau G, et al. Are cytokines linked to collagen breakdown during periodontal disease progression? J Periodontol. 2003;74(2):196-201.

8. Schulz S, Machulla HK, Altermann W, Klapproth J, Zimmermann U, Glaser C, et al. Genetic markers of tumour necrosis factor alpha in aggressive and chronic periodontitis. J Clin Periodontol. 2008;35(6):493-500.

9. Graves DT, Cochran D. The contribution of interleukin-1 and tumor necrosis factor to periodontal tissue destruction.J Periodontol. 2003;74(3):391-401.

10. Loos BG, John RP, Laine ML. Identification of genetic risk factors for periodontitis and possible mechanisms of action.J Clin Periodontol. 2005;32 Suppl 6:159-79.

11. Shimada Y, Tai H, Endo M, Kobayashi T, Akazawa K, Yamazaki K. Association of tumor necrosis factor receptor type $2+587$ gene polymorphism with severe chronic periodontitis. J Clin Periodontol. 2004;31(6):463-9.

12. Kinane DF, Shiba H, Hart TC. The genetic basis of periodontitis Periodontol 2000. 2005;39:91-117.

13. Donati M, Berglundh T, Hytonen AM, Hahn-Zoric M, Hanson LA Padyukov L. Association of the -159 CD14 gene polymorphism and lack of association of the -308 TNFA and Q551R IL-4RA polymorphisms with severe chronic periodontitis in Swedish Caucasians. J Clin Periodontol. 2005;32(5):474-9.

14. Chou DH, Lee W, McCulloch CA. TNF-alpha inactivation of collagen receptors: implications for fibroblast function and fibrosis. $J$ Immunol.1996;156(11):4354-62.

15. Costa AM, Guimaraes MC, de Souza ER, Nobrega OT, Bezerra AC Interleukin-6 (G-174C) and tumour necrosis factor-alpha (G308A) gene polymorphisms in geriatric patients with chronic periodontitis. Gerodontology. 2010;27(1):70-5.

16. Heidari Z, Mahmoudzadeh-Sagheb H, Rigi-Ladiz MA, Taheri M, Moazenni-Roodi A, Hashemi M. Association of TGF-beta1-509 C/T, $29 \mathrm{C} / \mathrm{T}$ and $788 \mathrm{C} / \mathrm{T}$ gene polymorphisms with chronic periodontitis: a case-control study. Gene. 2013;518(2):330-4.

17. Takashiba S, Naruishi K. Gene polymorphisms in periodontal health and disease. Periodontol 2000. 2006;40:94-106.

18. Taylor JJ, Preshaw PM, Donaldson PT. Cytokine gene polymorphism and immunoregulation in periodontal disease. Periodontol 2000. 2004;35:158-82.

19. Yoshie H, Kobayashi T, Tai H, Galicia JC. The role of genetic polymorphisms in periodontitis. Periodontol 2000. 2007;43:102-32.

20. Fassmann A, Holla LI, Buckova D, Vasku A, Znojil V, Vanek J. Polymorphisms in the $+252(\mathrm{~A} / \mathrm{G})$ lymphotoxin-alpha and the $-308(\mathrm{~A} / \mathrm{G})$ tumor necrosis factor-alpha genes and susceptibility to chronic periodontitis in a Czech population. J Periodontal Res. 2003;38(4):394-9.

21. Folwaczny M, Glas J, Torok HP, Mende M, Folwaczny C. Lack of association between the TNF alpha G-308 A promoter polymorphism and periodontal disease. J Clin Periodontol. 2004;31(6):449-53.

22. Soga Y, Nishimura F, Ohyama H, Maeda H, Takashiba S, Murayama Y. Tumor necrosis factor-alpha gene (TNF-alpha) -1031/-863, -857 single-nucleotide polymorphisms (SNPs) are associated with severe adult periodontitis in Japanese. J Clin Periodontol. 2003;30(6):524-31.

23. Galbraith GM, Hendley TM, Sanders JJ, Palesch Y, Pandey JP. Polymorphic cytokine genotypes as markers of disease severity in adult periodontitis. J Clin Periodontol. 1999;26(11):705-9.

24. Armitage GC. Development of a classification system for periodontal diseases and conditions. Ann Periodontol.1999;4(1):1-6.

25. Solhjoo S, Mahmoudzadeh Sagheb H, Heidari Z, Hashemi M, Rigi Ladez M. Association between TNF- $\alpha(-308 \mathrm{G} \rightarrow \mathrm{A})$ Gene Polymorphism and Chronic Periodontitis. Zahedan J Res Med Sci. 2013:10-4.

26. Howard V, Reed M. Unbiased stereology: three-dimensional measurement in microscopy.United States: Garland Science; 2004.

27. Heidari Z, Mahmoudzadeh-Sagheb H, Moudi B. A quantitative study of sodium tungstate protective effect on pancreatic beta cells in streptozotocin-induced diabetic rats. Micron. 2008;39(8):1300-5.

28. Seguier S, Godeau G, Leborgne M, Pivert G, Brousse N. Quantitative morphological analysis of Langerhans cells in healthy and diseased human gingiva. Arch Oral Biol. 2000;45(12):1073-81.

29. Seguier S, Godeau G, Brousse N. Collagen fibers and inflammatory cells in healthy and diseased human gingival tissues: a comparative and quantitative study by immunohistochemistry and automated image analysis. J Periodontol. 2000;71(7):1079-85.

30. Seguier S, Godeau G, Brousse N. Immunohistological and morphometric analysis of intra-epithelial lymphocytes and Langerhans cells in healthy and diseased human gingival tissues. Arch Oral Biol. 2000;45(6):441-52.

31. Kornman KS, di Giovine FS. Genetic variations in cytokine expression: a risk factor for severity of adult periodontitis. Ann Periodontol. 1998;3(1):327-38.

32. Graves DT, Fine D, Teng YT, Van Dyke TE, Hajishengallis G. The use of rodent models to investigate host-bacteria interactions related to periodontal diseases. JClin Periodontol. 2008;35(2):89-105. 
33. Craandijk J, van Krugten MV, Verweij CL, van der Velden U, Loos BG. Tumor necrosis factor-alpha gene polymorphisms in relation to periodontitis. J Clin Periodontol. 2002;29(1):28-34.

34. Moreira PR, Costa JE, Gomez RS, Gollob KJ, Dutra WO. TNFA and IL10 gene polymorphisms are not associated with periodontitis in Brazilians. Open Dent J. 2009;3:184-90.

35. Settin A, Ismail A, El-Magd MA, El-Baz R, Kazamel A. Gene poly- morphisms of TNF-alpha-308 (G/A), IL-10(-1082) (G/A), IL-6(-174) $(\mathrm{G} / \mathrm{C})$ and IL-1Ra (VNTR) in Egyptian cases with type 1 diabetes mellitus. Autoimmunity. 2009;42(1):50-5.

36. de Jong BA, Westendorp RG, Bakker AM, Huizinga TW. Polymorphisms in or near tumour necrosis factor (TNF)-gene do not determine levels of endotoxin-induced TNF production. Genes Immun. 2002;3(1):25-9. 